\title{
Improving fatigue performance of alumino-thermic rail welds
}

\author{
M. Jezzini-Aouad ${ }^{1,2, a}$, P. Flahaut ${ }^{1,2, b}$, S. Hariri, 2, c , D. Zakrzewski ${ }^{1,2, d}$ and \\ L. Winiar ${ }^{3, \mathrm{e}}$ \\ ${ }^{1}$ Univ. Lille Nord de France, F-59500 Lille, France \\ ${ }^{2}$ EMDouai, MPE-TPCIM, F-59508 Douai, France \\ ${ }^{3}$ Railtech International, Zone industrielle du Bas Pré, 59590 Raismes, France

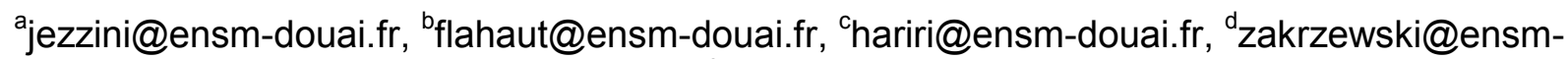 \\ douai.fr, ${ }^{\mathrm{e}}$ Iwiniar@railtech.fr
}

Keywords: alumino-thermic weld / residual stress / fatigue / microstructure / rail.

\begin{abstract}
Rail transport development offers economic and ecological interests. Nevertheless, it requires heavy investments in rolling material and infrastructure. To be competitive, this transportation means must rely on safe and reliable infrastructure, which requires optimization of all implemented techniques and structure. Rail thermite (or alumino-thermic) welding is widely used within the railway industry for in-track welding during re-rail and defect replacement. The process provides numerous advantages against other welding technology commonly used. Obviously, future demands on train traffic are heavier axle loads, higher train speeds and increased traffic density. Thus, a new enhanced weld should be developed to prevent accidents due to fracture of welds and to lower maintenance costs.

In order to improve such assembly process, a detailed metallurgical study coupled to a thermomechanical modeling of the phenomena involved in the rail thermite welding process is carried out. Obtained data enables us to develop a new improved alumino-thermic weld (type A). This joint is made by modifying the routinely specified procedure (type B) used in a railway rail by a standard gap alumino-thermic weld. Joints of type A and B are tested and compared. Based on experimental temperature measurements, a finite element analysis is used to calculate the thermal residual stresses induced. Besides, experimental investigation was carried out in order to validate the numerical model. Hence, X-Ray diffraction has been used to map the residual stress field that is generated in welded rail of types A and B. In the vicinity of the weld, the residual stress patterns depend on the thermal conditions during welding. Their effect on fatigue crack growth in rail welds is studied. In the web region, both longitudinal and vertical components of residual stresses are tensile, which increases the susceptibility of that region to crack initiation and propagation from internal material defects. Indeed, weld fracture in track initiates at the web fillet. Thus, to be closer to real issue, fatigue tests specimens has been defined within the split-web area. Fatigue tests was performed on the defined specimens, welded by conventional and improved processes and obtained results adjudicates on the new advances.
\end{abstract}

\section{Introduction}

Rail joints are the weakest units in the track structure. Railway rails are made in various length up to about $100 \mathrm{~m}$. In the past the most common method of joining sections was by bolting. In traditional bolted-joint track, there is differential movement of the running surface at the rail ends that creates severe wear and batter conditions under train traffic [1,2]. The dynamic interaction between wheels and rail joints not only contributes to the rail end damage, but also degrades the cross ties, fasteners, ballast and even the subgrade. Wherever possible, rails are now joined by welding which is a cheaper process and produces a superior joint. Probably, the most common technique for joining the rail in track on-site, for various reasons including easier alignment and other on-site factors (simplicity, portability and economy), is alumino-thermic welding [2,3]. A large number of alumino-thermic rail welds are made in track each year using standard procedures and a very high 
proportion are reliable [3], however, some do fail. Hence, this process should continue to be studied for its optimization and improvement. Different residual stress patterns generated by aluminothermic welding may contribute to the failures and they must be controlled. Compressive residual stresses are generally beneficial in that it would inhibit the initiation and propagation of fatigue cracks from surface defects. In contrast, tensile stresses increase the susceptibility to crack initiation and propagation from internal material defects. Whether the residual stresses effect is beneficial or detrimental to the structure reliability, we will seek either to develop them or to avoid them.

Improving the behavior in service of welded track structure must start through the analysis and understanding of metallurgical, physical and mechanical phenomena involved in the welding process. Thus, this work focuses on the reliability of alumino-thermic welded rails. After an overview of the method used, we will try to understand the phenomena involved in the generation of residual stresses. These phenomena once mastered, it can then act on different parameters to obtain a distribution and levels of residual stresses that increase resistance to service. This improvement is visible through the results of fatigue tests performed. In this investigation, two types of thermite welds (A and B) are studied. The welding-type B made with the standard PLR process used in France and type $\mathrm{A}$ is one developed for this study.

\section{Weld Fabrication}

A full-scale laboratory thermite welding was conducted in the RailTech International laboratory (Raismes- France). The parent rail used in welding was a $60 \mathrm{~kg} / \mathrm{m}$ rail (profil 60E1). A RailTech standard PLR thermite welding kits and procedures, using a one-shot crucible, were used in this study. The chemical analyses for the rail and weld metal are given in Table 1. Depending on the tests, two pieces of approximately 350 to $650 \mathrm{~mm}$ long new rail were lined up and placed on a support. The rails were carefully aligned, with the ends raised about $1 \mathrm{~mm}$ to allow drop on cooling, and the gap between them was adjusted to $25 \mathrm{~mm}$. A standard mold was assembled and fitted, sealed with luting sand and preheated for 4-5 minutes ( 3 bars) using the induction air torch to ensure that the assembly was dry. After preheating, the loaded welding crucible was put over the mold and the thermite charge was ignited. The exothermic reaction produced caused the charge to melt and the liquid metal was poured into the weld cavity. After pouring, the welds were allowed to cool before the mould shoe, the weld top, and the risers were removed.

For the weld type A, a new step is added to the standard procedure. In fact, in this step the welded rail is subjected to rapid cooling in order to reduce the post-weld time elapsed before to reach $350^{\circ} \mathrm{C}$ (temperature at which the train is allowed to roll).

\begin{tabular}{cccccc}
\hline Specimen & $\mathbf{C}[\%]$ & Si[\%] & Mn[\%] & Cr[\%] & Al[\%] \\
\hline Weld & 0,721 & 0,722 & 0,909 & 0,100 & 0,265 \\
Rail & 0,735 & 0,310 & 1,115 & 0,030 & 0,002 \\
\hline
\end{tabular}

Table 1: Chemical compositions of parent rail and completed thermite weld (wt \%)

\section{Weld Microstructure}

In order to reveal the weld microstructure and the extent of the melted zone (MZ) and heat-affected zone (HAZ), alumino-thermic welds were sectioned, polished and etched with 3\% nital for metallurgical observation. Sections reveal that the $M Z$ varies from $40 \mathrm{~mm}$ (head \& foot) to $50 \mathrm{~mm}$ (web), with a 'vase' shape (Fig. 1). In fact, in the head and foot regions, where the rail sections are thickest, there is least melting of the adjacent rail metal. The MZ is surrounded by a heat-affected zone that varies from 15 to $25 \mathrm{~mm}$. Samples were then examined using a scanning electron microscopy (SEM). Whatever the weld type is A or B, there are three successive zones starting from the weld centerline to the molten / base metal interface: a zone with equiaxed grains in size up to 1 $\mathrm{mm}$, then a columnar region and finally, an area composed of small equiaxed crystals at the cold interface. 
Indeed, when the temperature drops locally a few degrees below the liquidus temperature, solidification starts with nucleation of solid metal on various heterogeneities. Then, the weld solidification leads to pearlite lamellae formation with ferrite at grains boundaries (Fig. 2). These microstructures are responsible, at least partially, of the brittle fracture of welds $[4,5,6]$. Evidence of columnar growth that occurred during the cooling process is apparent in directions roughly from the boundary of the weld to near the centerline (Fig. 3). The MZ/HAZ boundary is strongly marked by a refinement of pearlitic grains at the HAZ (Fig. 3).
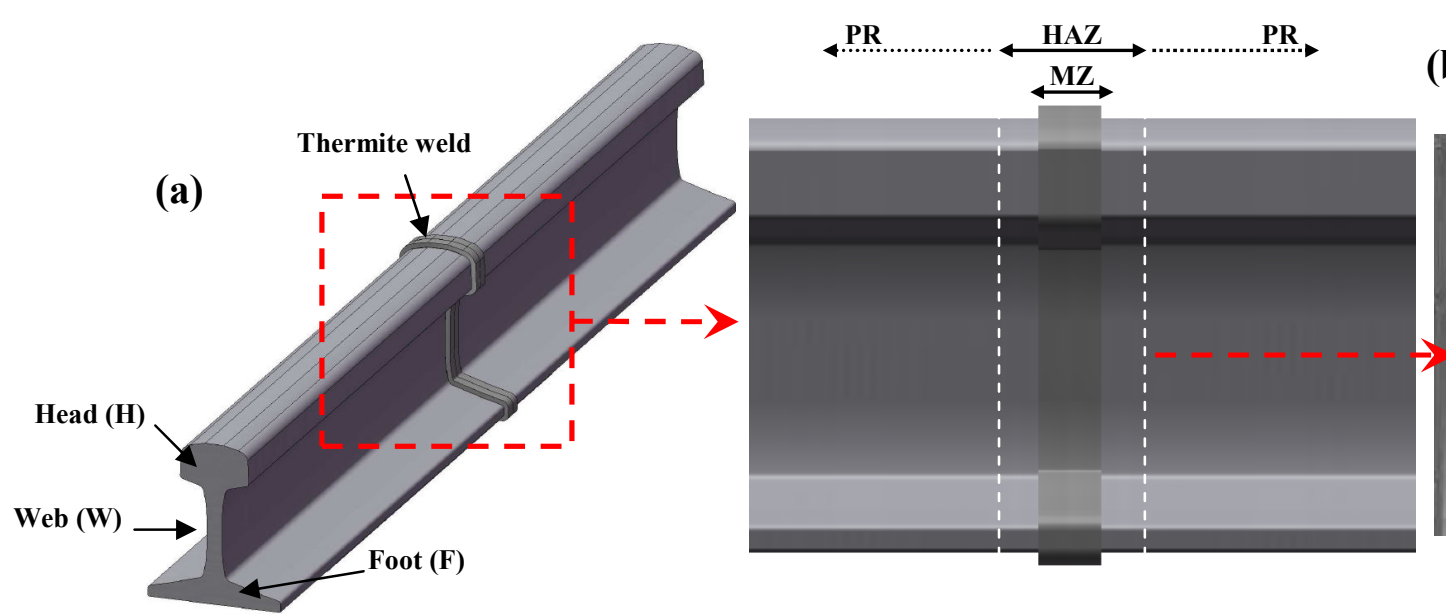

(b)

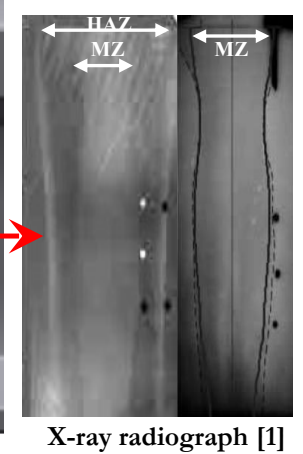

Fig. 1: (a) Geometry of a aluminothermite welded rails showing its Head, Web and foot; (b) Vertical central section of a thermite weld, polished and etched by Nital, showing the extent of the melted (MZ) and the heat-affected zones (HAZ) [1].

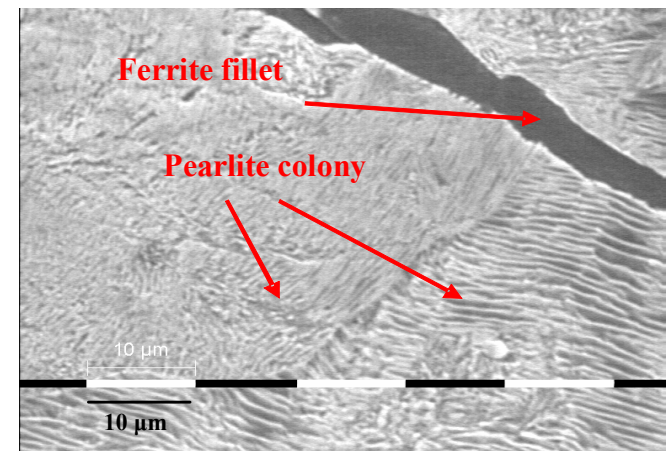

Fig. 2: A typical microstructure of thermite weld metal showing pearlite colonies and ferrite on the grain boundary

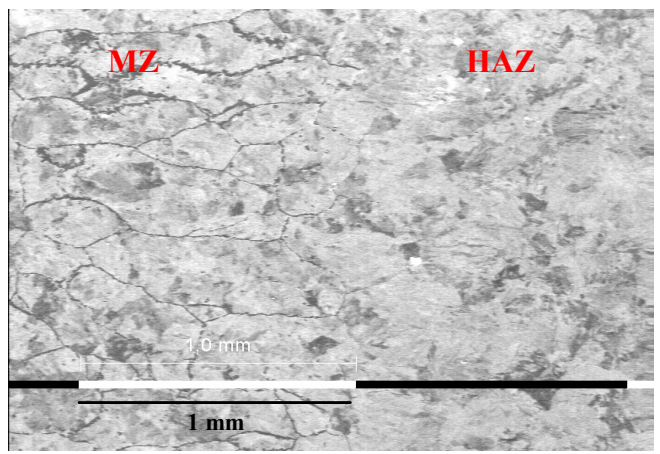

Fig. 3: Interface between weld metal (MZ) and the $\mathrm{HAZ}$ where pearlite structure is finer

\section{Tensile Tests}

Uniaxial tensile tests were performed on cylindrical specimens, machined from the rails head, web and foot, of alumino-thermic welds type A and B. In order to characterize the different zones produced by thermite welding, the melted zone (MZ), heat affected zone (HAZ) and parent rail (PR) within the tensile specimens were instrumented by strain gauges (Fig. 4).

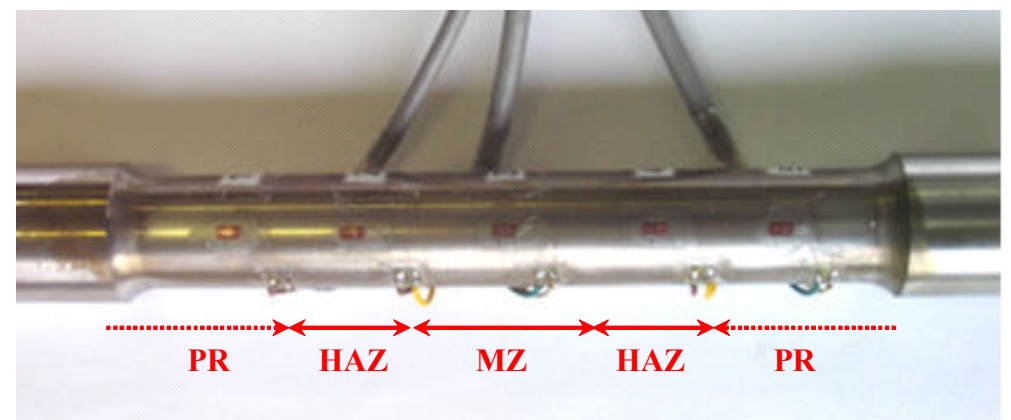

Fig. 4: Tensile test specimen within MZ, HAZ and PR instrumented by strain gauges 
The mechanical properties are given in Fig. 5 and 6. It is noted that either for type A or B, the yield strength of parent metal (PR) is not homogeneous in the head (H), web (W) and foot (F) of the rail (Fig 1 (a)). This is may be due to manufacturing processes, in particular, rail kneading. The level of Young's modulus and the yield strengths of the HAZ and MZ for types A and B remained equivalent. These parameters are more pronounced in the HAZ compared to other zones. The yield strength decreases slightly in the MZ for type A compared with type B.

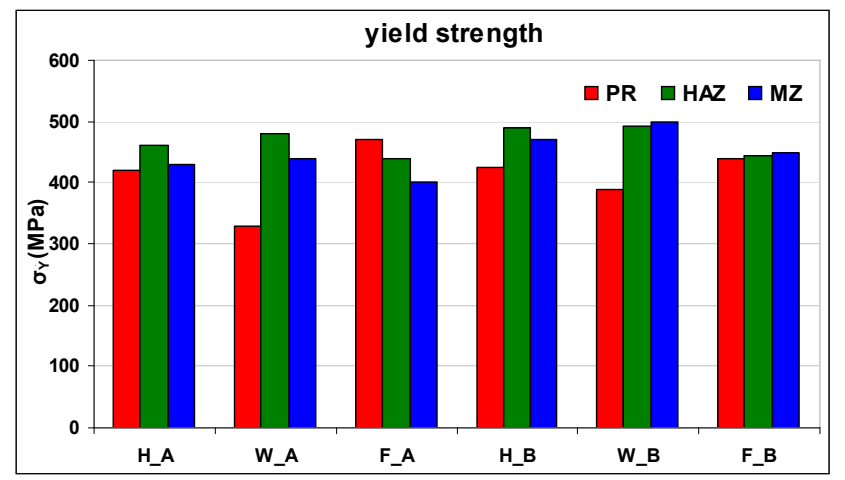

Fig. 5: Comparison between yield strength of welds types $\mathrm{A} \& \mathrm{~B}$. Where, $\sigma_{\mathrm{Y}}$ is determined for the MZ, $\mathrm{HAZ}$ and PR from tensile tests on specimens machined from the $\mathrm{H}, \mathrm{W}$ and $\mathrm{F}$ of thermite weld

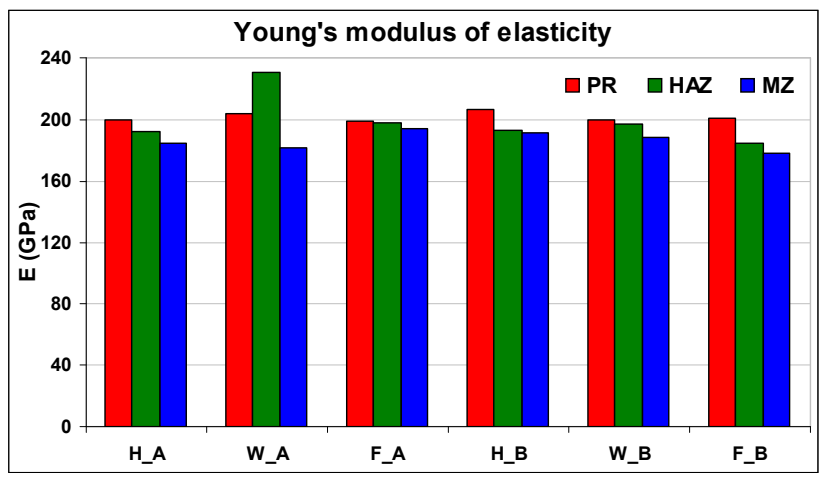

Fig. 6: Comparison between Young's modulus of welds types $\mathrm{A} \& \mathrm{~B}$. Where, $\mathrm{E}$ is determined for the $\mathrm{MZ}, \mathrm{HAZ}$ and PR from tensile tests on specimens machined from the $\mathrm{H}, \mathrm{W}$ and $\mathrm{F}$ of thermite weld

\section{Residual Stresses}

Within the melted zone (MZ), the heat-affected zone (HAZ) and the adjacent parent material where the thermal softening and thermal strains caused by the heat flow from the weld are sufficient to cause yielding during welding, the residual stress field are dominated by the weld-induced residual stresses. At greater distances from the weld, the residual stresses after welding are a function of the superimposition of the weld-induced residual stresses and any pre-existing residual stresses in the parts being joined. This superimposition may be in the linear elastic or nonlinear elastic plastic or creep range, depending on combined magnitude of the residual stresses and the mechanical properties of the parent material [7].

Residual stresses before welding may be caused by thermal or mechanical processes during materials manufacture or fabrication operations. Material or product manufacturing operations that cause significant residual stresses include casting, forging, rolling, heat treatments, quenching, straightening and carburisation.

$\mathrm{X}$-ray diffraction technique is used to investigate the distribution of residual stresses across the alumino-thermic welded rail. In crystalline materials such as metals and their alloys, the constituent atoms are regularly arranged on the crystal lattice, which has dimensions precisely defined and characteristic for a particular alloy. The principle of diffraction is to measure the spacings between atomic planes in materials. When a beam of X-rays is incident upon a polycrystalline material the rays are scattered in specific directions defined by the Bragg equation (Eq. 1):

$$
\lambda=2 \mathrm{~d} \sin \theta .
$$

Where $\lambda$ is the $\mathrm{X}$-rays wavelength, $\mathrm{d}$ is the interplanar spacing and $\theta$ is the incidence angle. If the material is stressed, the lattice dimension is changed by $\delta \mathrm{d}$. Measurements were made on thermite welded rails using parameters given in Table 2.

\begin{tabular}{ccccc}
\hline Cryst. Latt. & Plane $\{$ hkl $\}$ & $\boldsymbol{\lambda}_{\mathbf{K a}}$ & $\mathbf{2 \theta}_{\mathbf{0}}$ & Pen $(\boldsymbol{\psi}=\mathbf{0})$ \\
\hline CC & $\{211\}$ & $\operatorname{Cr} 2,29[\mathrm{~nm}]$ & $156,41^{\circ}$ & $5,8[\mu \mathrm{m}]$ \\
\hline
\end{tabular}

Table 2: Ferritic steel parameters used for X-ray diffraction 
After welding and cooling, the residual stresses are determined at different locations and their distribution is compared to temperature evolution throughout the welding operation. To do so, holes were drilled in the rail at regular distances $(50,100$ and $150 \mathrm{~mm})$ from the weld centerline to accept thermocouple probes. K-type thermocouples were used for the rail temperature measurement. A National Instrument multi-channel system was used to collect data during welding and cooling. Typical temperature measurements in the rail head for types A and B are shown (Fig. 7). Similar temperature history curves were also obtained in the rail web and base. Distribution of longitudinal residual stresses is given in Fig. 8.

Within the MZ and the HAZ, residual stress field is dominated by the weld-induced residual stresses. These stresses are maximal at the MZ (35-35mm) and HAZ (50-50mm) where temperatures exceeded $650^{\circ} \mathrm{C}$ before cooling (Fig. 7, Fig. 8). The level of these stresses decreases moving away from the MZ.

Initial results show that levels, signs and distributions of stresses depend on the thermal history. For example, the compressive residual stresses are highest in welded rails where the temperature gradients were more pronounced (Fig. 7, Fig. 8). Fig. 8 shows obtained results for both types A \& $\mathrm{B}$, a higher compression stress level is observed for type A.

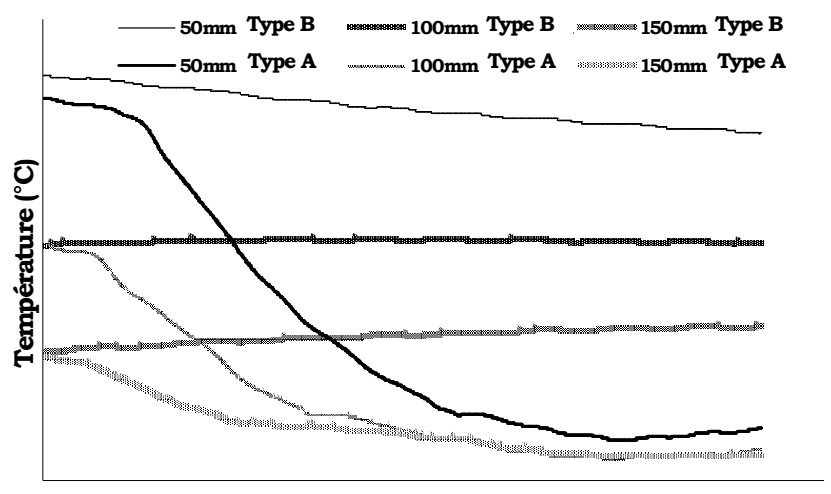

Time (s)

Fig. 7: Comparisons between measured temperature in the rail head of welds types $A \& B$ at distances of 50, 100 and $150 \mathrm{~mm}$ from the weld centreline

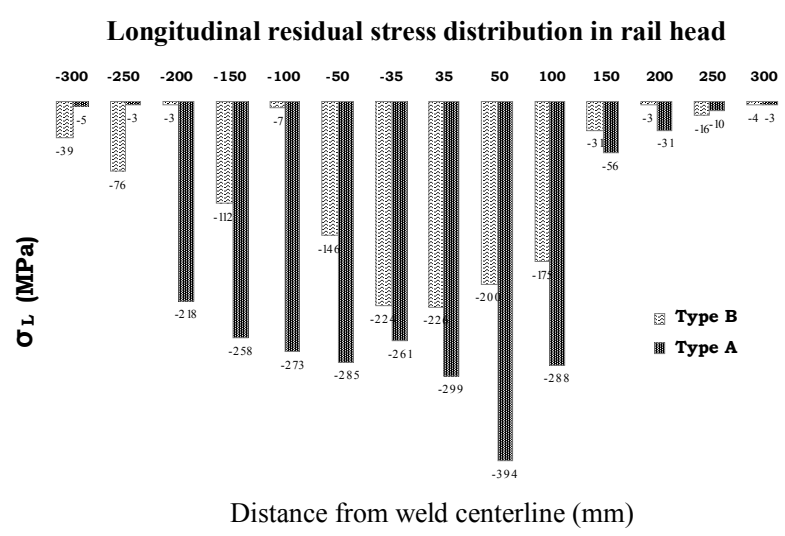

Fig. 8: Comparisons of residual stresses distribution in the rail head, determined using $X$-ray diffraction, between thermite welded rails of types A \& B

\section{Fatigue Tests}

Fatigue tests were performed on type A and B welds in order to compare the two process and to verify whether type A provide improvements of the rails fatigue life or not. First, tests were carried out according to the European four point bending fatigue test draft standard EN 14730-1 [8]. Specimens were full scale $25 \mathrm{~mm}$ gap thermite rail welds, $1200 \mathrm{~mm}$ rail long, and applying the load on the running surface i.e. the rail head. In this case, the head is in compression and the foot is in tension. The fatigue fractures sites were located at the web-base fillet of the rail. Notwithstanding, observed in-track failures, for this study case, always initiate at the HAZ head-web fillet. Hence, to approximate in-track fracture conditions, fatigue tests were performed in reverse order, i.e. foot in compression and head in traction. Using this new method, failures initiate at the head-web fillet, which is similar to those obtained in-track.

Preliminary results performed with the reversed fatigue tests on full-scale specimens, support assumptions on the beneficial influence of compressive residual stresses on fatigue life. Welds of type B tested failed after about two million cycles where type A welds stand the test up to about ten million cycles.

The validation of a fatigue test result requires a large number of specimens. However, tests on full-scale specimens are very expensive, so it is necessary to set up a scale-down specimen. This sample should keep the main characteristics of a full-scale welded rail. Given that in-track failures 
initiate from the head-web fillet, the scale-down specimens are made by machining while keeping untouched this zone (Fig. 9).

Reversed fatigue tests were performed on scale-down specimens of types A and B. Results confirm those obtained on full-scale specimens. An improvement of about $30-40 \%$ is obtained for the welding-type A developed in this work.
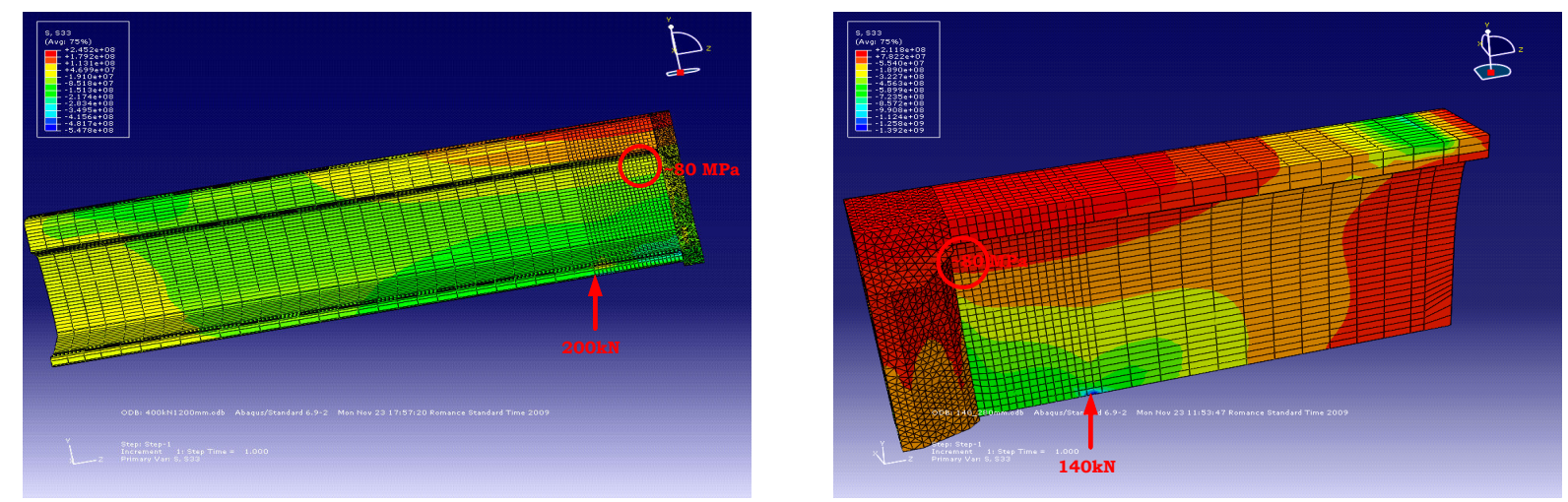

Fig. 9: Full-scale (left figure) / scale-down (right figure) specimens design basis using finite element method

\section{Summary}

This work aims to improve the service performance of alumino-thermic rail welds. A metallurgical and thermal study enabled to validate a new thermite welding process. The standard and new methods were compared.

The residual stresses associated with the two methods have been determined. Results show an increase of maximal longitudinal compressive stresses associated with the new process.

Results of fatigue four points bending tests performed, on full and scale-down specimens, confirm the improved resistance of the new weld type.

\section{References}

[1] Y. Chen, A heat transfer modelling study of rail thermite welding, $\mathrm{PhD}$ Dissertation, University of Illinois at Urbana-Champaign (2004).

[2] W.W. Hay, Railroad Engineering, edited by John Wiley \& Sons, New York (1982).

[3] P.J. Webster, G. Mills, X.D. Wang, W.P. Kang and T.M. Holden: Journal of Strain Analysis Vol. 32 (1997), pp. 389-400.

[4] F.T. Lee: Welding Journal Vol. 85 n¹ (2006), pp. 24-29.

[5] L.C. Schroeder and D.R. Poirier: Proc. of Railroad Rail Welding (1983), pp. 21-59.

[6] J. Myers, G.H. Geiger and D.R. Poirier: Welding Journal Research Supplement Vol 61 (1982), pp. 258-268.

[7] R.H. Leggatt: Int. J. Pressure Vessels Piping Vol 85 (2008), pp. 144-151.

[8] EN 14730-1: European standard (2006). 